\title{
Aortic dissection extending from the brachiocephalic artery during transradial coronary catheterization: a case report
}

\author{
Kihyun Kim, Yeon Seong Kim, Yeongmin Woo and Sang-Yong Yoo ${ }^{*}$ (D)
}

\begin{abstract}
Background: latrogenic acute aortic dissection (AD) is an extremely rare but devastating complication during cardiac catheterization. It can be treated conservatively if it develops in a retrograde form or manifests as an intramural hematoma (IMH) with a micro-intimal tear in the absence of instability. However, only a few reports exist on its natural course and long-term outcomes.

Case presentation: A 78-year-old woman presented to the emergency department with acute chest discomfort. Elective cardiac catheterization was performed via the right radial artery. The patient's brachiocephalic artery was so tortuous that the hydrophilic soft guidewire had to be exchanged for a stiffer one. However, the stiff wire caused the dissection of a tortuous brachiocephalic artery that extended from the sinuses of Valsalva to the proximal descending aorta. Emergent computed tomography showed crescentic aortic wall thickening without a dissection flap. The patient had cardiac tamponade and a gradually thickening thrombosed false lumen. Although the patient was unstable during the first 2 weeks, she was stabilized during hospital stay with only conservative treatment. Consequently, she has been well for over 5 years.
\end{abstract}

Conclusions: Even though the patient showed ominous findings, a good prognosis was expected because the AD was mainly retrograde. Furthermore, the thrombosed false lumen mimicked an $\mathrm{IMH}$ on imaging. To the best of our knowledge, this is the first report of an extensive iatrogenic AD originating from the brachiocephalic artery during right transradial catheterization that was treated conservatively despite clinical instability.

Keywords: latrogenic aortic dissection, Transradial catheterization, Brachiocephalic trunk, Conservative treatment, Case report

\section{Background}

Acute iatrogenic aortic dissection (AD) is an extremely rare but potentially lethal complication during cardiac catheterization. Only a few studies have been conducted on its natural history and long-term outcomes. Previous case series have suggested that iatrogenic ADs extending $>40 \mathrm{~mm}$ above the ascending aorta should be treated surgically. However, recent studies have reported that

\footnotetext{
*Correspondence: bovio@naver.com

Department of Cardiology, Gangneung Asan Hospital, University of Ulsan College of Medicine, 38 Bangdong-gil, Sacheon-myeon, Gangneung-si, Gangwon-do 25440, Republic of Korea
}

iatrogenic AD can be treated conservatively if it develops in a retrograde form or manifests as an intramural hematoma (IMH) with a micro-intimal tear. Here, we report an extremely rare case of an acute DeBakey Type I $\mathrm{AD}$ that occurred during right transradial cardiac catheterization. Despite hypotension and increasing $\mathrm{IMH}$ thickness, the patient was successfully treated without surgery.

\section{Case presentation}

A 78-year-old woman with a history of hypertension and apical hypertrophic cardiomyopathy presented to the

C The Author(s). 2020 Open Access This article is licensed under a Creative Commons Attribution 4.0 International License, which permits use, sharing, adaptation, distribution and reproduction in any medium or format, as long as you give appropriate credit to the original author(s) and the source, provide a link to the Creative Commons licence, and indicate if changes were made. The images or other third party material in this article are included in the article's Creative Commons licence, unless indicated otherwise in a credit line to the material. If material is not included in the article's Creative Commons licence and your intended use is not permitted by statutory regulation or exceeds the permitted use, you will need to obtain permission directly from the copyright holder. To view a copy of this licence, visit http://creativecommons.org/licenses/by/4.0/ The Creative Commons Public Domain Dedication waiver (http://creativecommons.org/publicdomain/zero/1.0/) applies to the data made available in this article, unless otherwise stated in a credit line to the data. 
emergency department with a 30-min history of atypical chest discomfort and dizziness. She was taking bisoprolol $2.5 \mathrm{mg}$ qd, lercanidipine $20 \mathrm{mg}$ qd, valsartan $160 \mathrm{mg}$ qd, spironolactone $12.5 \mathrm{mg} \mathrm{qd}$, and torsemide $5 \mathrm{mg} \mathrm{qd}$ for hypertension. She had no history of cigarette smoking, alcohol intake, or connective tissue disease and no family history of acute aortic syndrome. Her electrocardiogram (ECG) showed biphasic $\mathrm{T}$ wave inversions in leads V3-V6 and left ventricular hypertrophy (Fig. 1a). Biphasic $\mathrm{T}$ wave inversions in anterolateral leads could be due to apical hypertrophic cardiomyopathy as there was no interval change compared to a previous ECG, but the possibility of ischemic change could not be completely excluded. Chest X-ray revealed cardiomegaly and a tortuous and calcified aorta (Fig. 1b and c). Echocardiogram showed normal left ventricular ejection fraction (LVEF) without regional wall motion abnormality (Additional file 1 and 2: Video S1-2).. Thus, Elective cardiac catheterization was performed via the right radial artery. Only aspirin was administered from 3 days before cardiac catheterization and 3000 units of heparin were administered after radial artery puncture on the day of cardiac catheterization. The patient's brachiocephalic artery was so tortuous that the 0.035 " hydrophilic soft guidewire had to be exchanged for a stiffer one. A 5-Fr Judkins right catheter was then introduced into the ascending aorta. The first contrast dye injection into the aortic root made a discrete dissection flap from the sinus of Valsalva to the origin of the brachiocephalic artery (Fig. 2a and Additional file 3: Video S3). Persistent dye staining within the dissection flap was observed on the final angiogram (Fig. 2b and Additional file 4: Video S4). Thus, the procedure was discontinued without coronary angiogram.

The patient's vital signs were stable, and there was no evidence of pericardial effusion on immediate
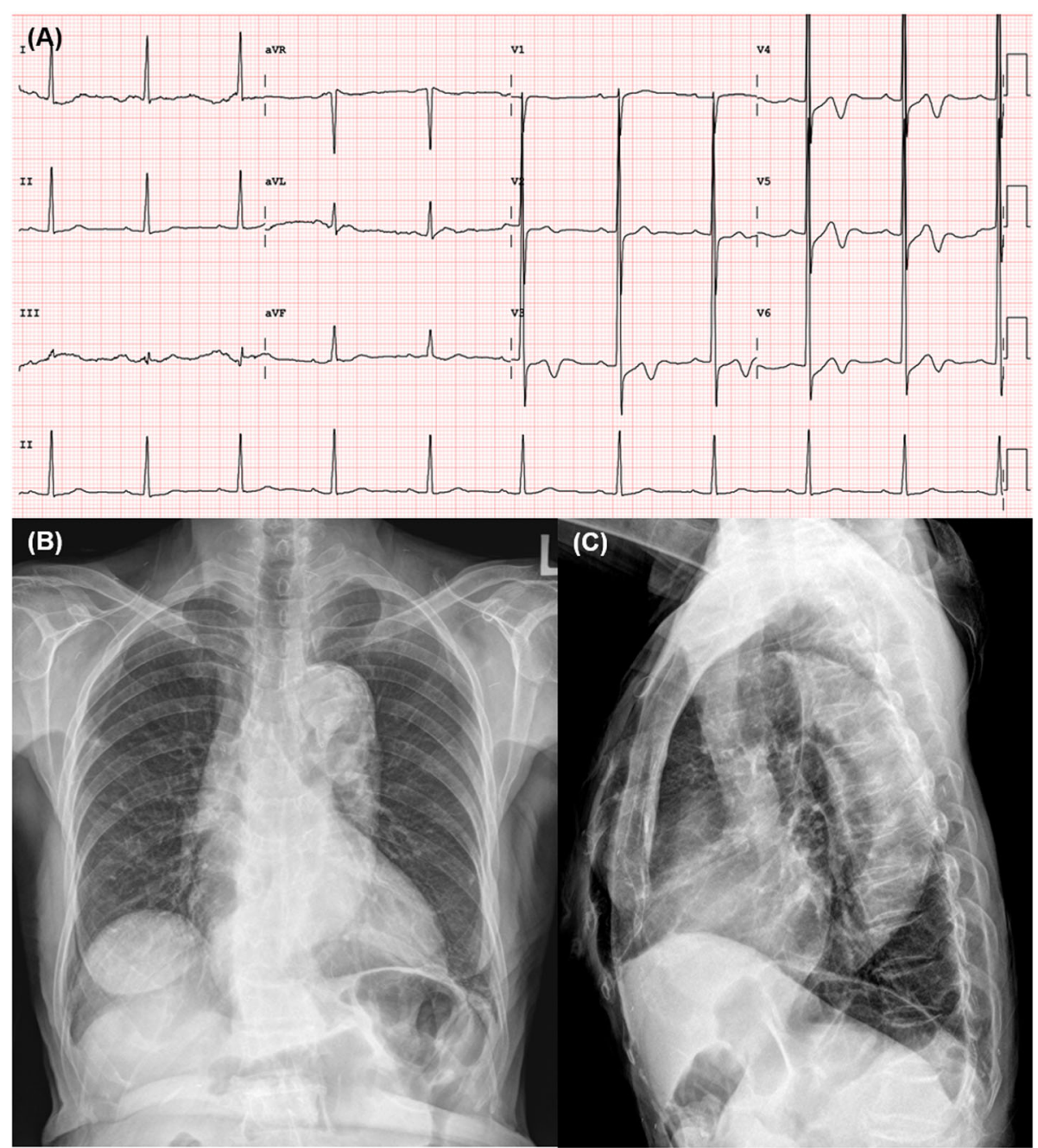

Fig. 1 Electrocardiogram (ECG) and chest X-rays before the catheterization procedurea ECG shows biphasic T wave inversions in leads V3-V6 and left ventricular hypertrophy without interval change; $\mathbf{b}$ and $\mathbf{c}$ Chest $X$-rays reveal cardiomegaly and a tortuous, calcified aorta 


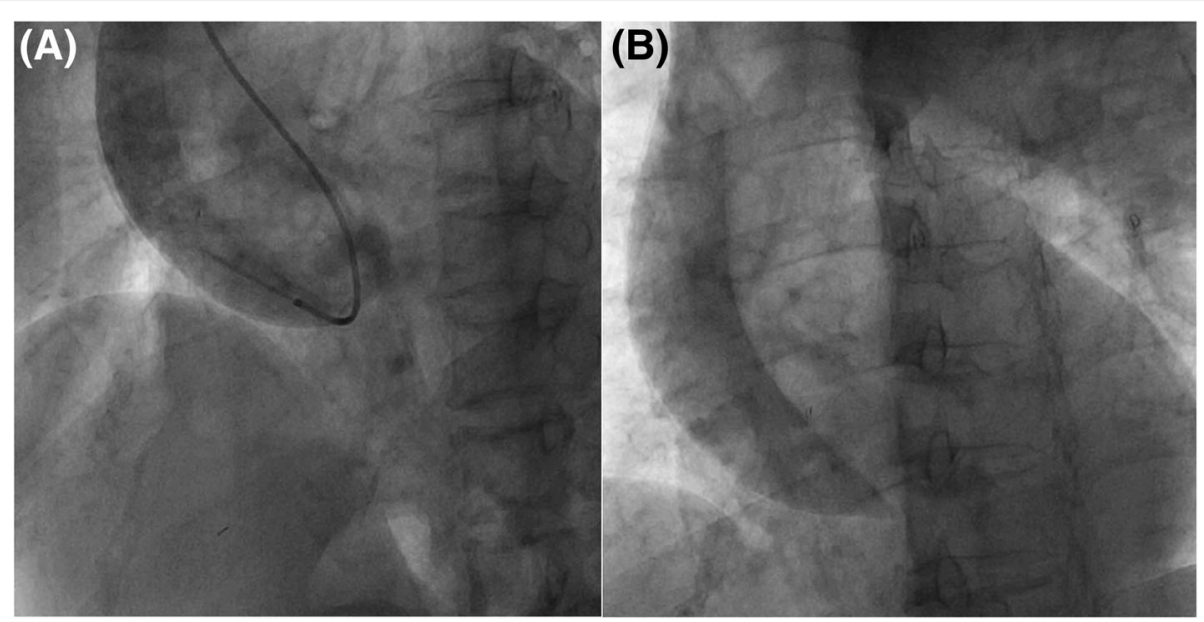

Fig. 2 Cardiac catheterization performed via right radial access. a After passage of the stiff wire through the tortuous brachiocephalic artery, the first injection of contrast dye in the aortic root reveals a discrete dissection flap from the sinus of Valsalva to the origin of the brachiocephalic artery; $\mathbf{b}$ The final angiogram shows persistent dye staining of the dissection flap

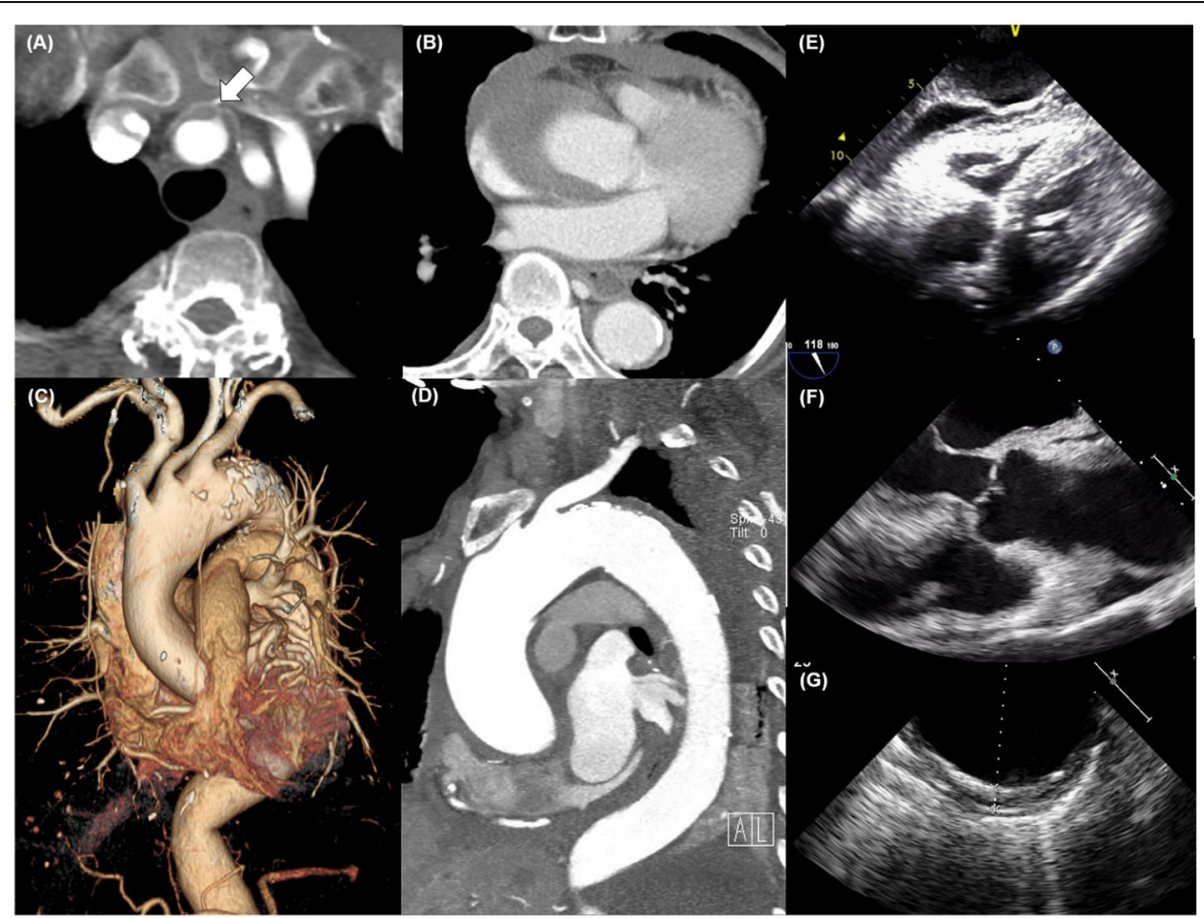

Fig. $\mathbf{3}$ a-d Computed tomography (CT) angiography and $\mathbf{e}$ transthoracic and $\mathbf{f}$-g transesophageal echocardiography (TEE) scans; $\mathbf{a}-\mathbf{b}$ Aorta CT angiography, axial plane. a The site of entry tear is suspected to be located in the proximal brachiocephalic artery (white arrow) but a dissection flap cannot be clearly observed; $\mathbf{b}$ This aortic dissection (AD) mimics an intramural hematoma (IMH) retrogradely extending to the sinuses of Valsalva resulting in pericardial effusion; $\mathbf{c}$ Three-dimensional reconstructed image and $\mathbf{d}$ Sagittal oblique reconstruction image of aorta CT angiography shows the extent of $\mathrm{AD}$ mimicking an $\mathrm{IMH}$ extending anterogradely to the proximal descending thoracic aorta; e subcostal view of transthoracic echocardiogram reveals newly developed, moderate amount of pericardial effusion; f TEE (135 degree long axis view) showed no definite dissection flap and intramural hematoma in the aortic root. $\mathrm{g}$ TEE (0 degree short axis view) revealed an IMH extending anterogradely to the proximal descending thoracic aorta 
echocardiography. Five hours later, however, the patient complained of chest discomfort and back pain. Her blood pressure (BP) dropped to $85 / 50 \mathrm{mmHg}$, and her pulse rate was $48 \mathrm{bpm}$. Emergent echocardiography and computed tomography $(\mathrm{CT})$ showed moderate amounts of pericardial effusion and crescentic aortic wall thickening without a dissection flap (Fig. 3a-g). The site of entry tear was suspected to be in the proximal brachiocephalic artery (Fig. 3a and Additional file 5: Video S5). These findings suggested an $\mathrm{AD}$ with a thrombosed lumen mimicking IMH. The AD extended in both directions: retrogradely, to the sinuses of Valsalva (Fig. 3b) and anterogradely, to the proximal descending thoracic aorta (Fig. 3c-d, g). Blood flow to the branches of the aortic arch was preserved (Fig. $3 \mathrm{c}-\mathrm{d}$ ).

Her BP stabilized temporarily with rapid infusion of normal saline and $6 \%$ hydroxyethyl starch, but soon fell again. So we decided on emergency surgery for the acute $\mathrm{AD}$, and at her request, she was immediately transferred to Asan Medical Center, Korea's largest referral hospital.
However, her BP did not drop again and chest discomfort and back pain also improved. Furthermore, followup CT, taken $5 \mathrm{~h}$ after the first CT showed a significant decrease in the IMH thickness from 19 to $4 \mathrm{~mm}$ at the mid-ascending aorta (Fig. 4a-b). Follow-up echocardiogram revealed normal LVEF with small amount of pericardial effusion and mild aortic regurgitation. Therefore, the surgery was withheld and she was monitored closely in the intensive care unit. For the first 3 days, intravenous esmolol was administered to control BP and pulse rate, and then changed to bisoprolol. Timeline of relevant events were presented in Table 1.

However, thereafter, the IMH thickness gradually increased to $11 \mathrm{~mm}$ until the second week (Fig. 4c-d). In the third week, there was no further increase in IMH thickness on follow-up CT. The patient remained stable and was discharged 3 weeks after hospitalization without surgery. She was prescribed bisoprolol $7.5 \mathrm{mg} \mathrm{qd}$, amlodipine $5 \mathrm{mg} \mathrm{qd}$, olmesartan $10 \mathrm{mg} \mathrm{qd}$, and spironolactone $12.5 \mathrm{mg}$ bid as discharge medications. After 3

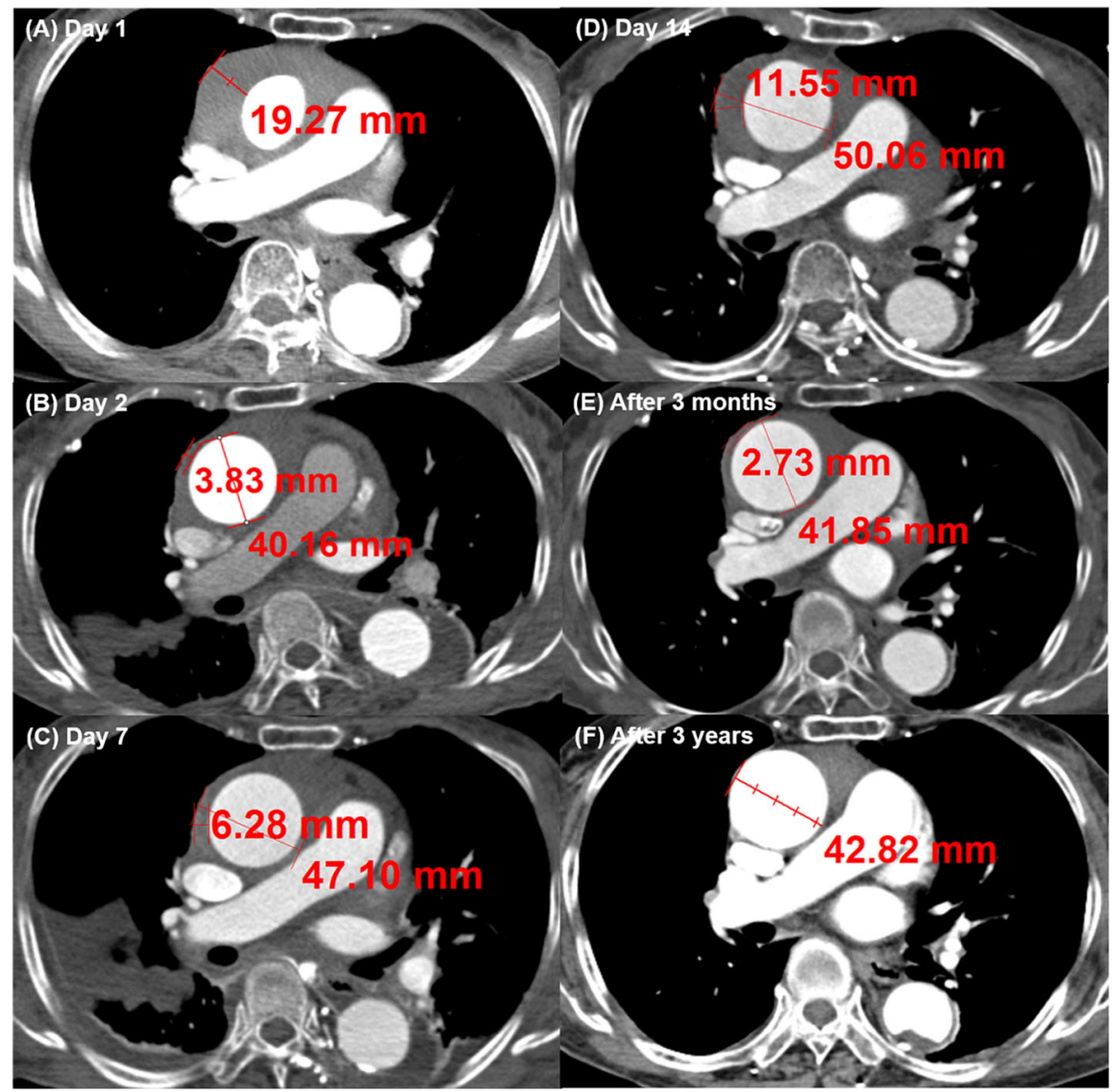

Fig. 4 Axial contrast-enhanced computed tomography (CT) showing the change in intramural hematoma (IMH) thickness at the mid-ascending aorta. $\mathbf{a}-\mathbf{b}$ The day after the occurrence of the catheter-induced aortic dissection, the IMH thickness is noted to decrease from 19 to 4 mm by conservative treatment; c-d However, it gradually increases to $11 \mathrm{~mm}$ until the second week. The diameter of the ascending aorta is $50 \mathrm{~mm}$; e-f After 3 months, the IMH thickness has decreased to $2.7 \mathrm{~mm}$. Follow-up CT after 3 years shows complete resolution of the IMH 
Table 1 Timeline of relevant events

\begin{tabular}{lll}
\hline Date & Time & Events \\
\hline 07-Apr-2015 & & Onset of chest discomfort \\
07-Apr-2015 & $15: 00$ & First hospitalization \\
14-Apr-2015 & $20: 30$ & Elective cardiac catheterization \\
& $21: 50$ & BP drop with chest discomfort and back pain \\
& $23: 20$ & Emergent aorta CT angiography \\
15-Apr-2015 & $02: 40$ & Decided to transfer to the referral hospital for emergency surgery \\
07-May-2015 & & Follow-up aorta CT angiography in the referral hospital \\
\hline
\end{tabular}

months, the IMH thickness decreased to $2.7 \mathrm{~mm}$, and it disappeared completely after 3 years. The diameter of the ascending aorta remained at $50 \mathrm{~mm}$ (Fig. 4e-f). Five years later, the patient remains well with medical treatment.

\section{Discussion and conclusions}

Acute iatrogenic AD is an extremely rare (incidence: $0.01-0.02 \%$ ) yet devastating complication during cardiac catheterization [1]. It may be classified into two main types: anterograde and retrograde. The former type can be treated with a stent, while the latter usually seals spontaneously with the collaboration of antegrade blood flow $[2,3]$. Due to the rarity of iatrogenic AD, only a few reports exist on its natural course and long-term outcomes [4].

In 2000, Dunning et al. reported nine cases of iatrogenic aortocoronary dissection and proposed a classification involving three grades [5]. Two cases were classified as class 3; both these patients underwent emergency surgery and died. Thus, it was recommended that surgical intervention be performed for class 3 dissections involving the cusp and extending $>40 \mathrm{~mm}$ above the ascending aorta.

In contrast, a recent study involving 74 cases and a median follow-up of 5 years reported that patients with iatrogenic $\mathrm{AD}$ involving ascending aorta had a good prognosis after the acute phase, regardless of coronary artery involvement and vascular access (femoral or radial) [6]. Only two patients with ischemic heart disease died of cardiogenic shock within a month of follow-up.

In most cases, iatrogenic $\mathrm{AD}$ occurring during cardiac catheterization is caused by mechanical trauma from a catheter, a guidewire, or other devices around an ostium of a coronary artery. There have been only two case reports of iatrogenic $\mathrm{AD}$ in which the intimal flap was reported to be located in the brachiocephalic artery. One patient underwent surgery [7] while the other was treated medically because of the absence of instability [8].

To the best of our knowledge, this is the first report of an extensive iatrogenic $\mathrm{AD}$ originating from the brachiocephalic artery during right transradial catheterization that was treated conservatively despite clinical instability. This was possible because the patient was re-stabilized while the patient was going to the referral hospital, which is $3 \mathrm{~h}$ away by car to receive emergency surgery, and the aortic dissection was greatly reduced in the follow-up CT scan. Hemorrhage into the pericardium could have resulted in cardiac tamponade. If the patient had not been transferred, she would have received an emergency surgery immediately because she was unstable at the beginning with also a pericardial effusion, which is a very important prognostic factor. For reference, the author's hospital is a referral hospital with 850 beds, 8 interventional cardiologists and 2 catheterization labs. We perform about 1300 coronary angiograms and 800 percutaneous coronary interventions annually.

The risk of iatrogenic dissection increased by inadvertent and aggressive manipulation of a wire or a catheter in heavily calcified vessels. Even though the patient showed ominous findings such as aggravated back pain, newly developed pericardial, and hypotension, a good prognosis could be possible because the AD was mainly retrograde. Furthermore, the thrombosed false lumen mimicked an IMH on imaging [2].

An iatrogenic AD may occur in the form of an IMH with a micro-intimal tear that cannot be easily detected on CT or transesophageal echocardiography [9]. For such variant forms of $\mathrm{AD}$, imaging findings are more important than clinical features. Interestingly, in Eastern countries, a type A IMH was more prevalent than classic AD (25.5\% vs. $10.9 \%)$. AD was managed by medical treatment more frequently $(80.8 \%$ vs. $48.8 \%)$ and was associated with lower hospital mortality (5.9\% vs. $33.3 \%)$ in Eastern countries than in Western countries [10].

To prevent such terrible complications, the operator should not manipulate the wire or catheter forcefully when resistance is encountered. It is a good practice to check the pressure before test injection of the contrast dye. Particularly, on encountering a tortuous vascular access, the operator should consider trying other routes of 
vascular access with a lower risk of dissection. If complications occur, it is important to discuss appropriate treatment strategies with other cardiologists, radiologists, and cardiac surgeons.

In the clinical practice of catheterization, operators should handle guidewires and catheters carefully to prevent potentially life-threatening complications. If an iatrogenic $\mathrm{AD}$ occurs, careful examination of imaging findings, an understanding of the mechanism of injury, vigilant monitoring of the patient's clinical course, and identification of the best treatment strategy are warranted.

\section{Supplementary information}

Supplementary information accompanies this paper at https://doi.org/10. 1186/s12872-020-01687-8.

Additional file 1: Video S1. Parasternal long axis view of transthoracic echocardiogram showed apical hypertrophic cardiomyopathy with normal left ventricular ejection fraction (LVEF).

Additional file 2: Video S2. Apical 2-chmabers view of transthoracic echocardiogram showed apical hypertrophic cardiomyopathy with normal LVEF.

Additional file 3: Video S3. Fluoroscopic anteroposterior view of the ascending aorta. The first contrast dye injection into the aortic root made a discrete dissection flap from the sinus of Valsalva to the origin of the brachiocephalic artery

Additional file 4: Video S4. Rotational fluoroscopy of the ascending aorta which shows persistent dye staining within the dissection flap

Additional file 5: Video S5. Axial contrast-enhanced computed tomography (CT) shows moderate amounts of pericardial effusion and crescentic aortic wall thickening without a dissection flap. The site of entry tear is suspected to be in the proximal brachiocephalic artery. This aortic dissection (AD) mimics an intramural hematoma $(\mathrm{IMH})$ extending bidirectionally.

\section{Abbreviations}

AD: Aortic dissection; IMH: Intramural hematoma; ECG: Electrocardiogram; CT: Computed tomography; LVEF: Left ventricular ejection fraction

\section{Acknowledgments}

We would like to thank Editage (www.editage.co.kr) for English language editing.

\section{Authors' contributions}

All authors made substantial contributions to the conception and design of the work. KK drafted the manuscript. YSK and YW contributed to the acquisition and interpretation of the relevant clinical record. YSK and YW edited and revised figures and video files. KK and SYY revised the manuscript. The authors have read and approved the final manuscript.

\section{Funding}

No funding was obtained for this study.

\section{Availability of data and materials}

All data generated or analysed during this study are included in this published article and its supplementary information files.

\section{Ethics approval and consent to participate}

Not applicable.

\section{Consent for publication}

Written informed consent was obtained from the patient for publication of this case report and any accompanying images.

\section{Competing interests}

The authors have no conflicts of interest to declare.

Received: 16 July 2020 Accepted: 25 August 2020

Published online: 31 August 2020

\section{References}

1. Leontyev S, Borger MA, Legare JF, Merk D, Hahn J, Seeburger J, Lehmann S, Mohr FW. latrogenic type a aortic dissection during cardiac procedures: early and late outcome in 48 patients. Eur J Cardiothorac Surg. 2012;41(3): 641-6.

2. Kim JB, Choo SJ, Kim WK, Kim HJ, Jung SH, Chung CH, Lee JW, Song JK. Outcomes of acute retrograde type a aortic dissection with an entry tear in descending aorta. Circulation. 2014;130(11 Suppl 1):S39-44.

3. Nunez-Gil IJ, Bautista D, Perez-Vizcaino MJ, Cerrato E, Salinas P, FernandezOrtiz A. Type a iatrogenic aortic dissection following catheterization without coronary involvement: long-term prognosis. Rev Esp Cardiol (Engl Ed). 2015; 68(3):254-5

4. Januzzi JL, Sabatine MS, Eagle KA, Evangelista A, Bruckman D, Fattori R, Oh JK, Moore AG, Sechtem U, Llovet A. latrogenic aortic dissection. Am J Cardiol. 2002;89(5):623-6.

5. Dunning DW, Kahn JK, Hawkins ET, O'Neill WW. latrogenic coronary artery dissections extending into and involving the aortic root. Catheter Cardiovasc Interv. 2000;51(4):387-93.

6. Nunez-Gil IJ, Bautista D, Cerrato E, Salinas P, Varbella F, Omede P, Ugo F, lelasi A, Giammaria M, Moreno R, et al. Incidence, management, and immediate- and long-term outcomes after iatrogenic aortic dissection during diagnostic or interventional coronary procedures. Circulation. 2015: 131(24):2114-9.

7. Noguchi K, Hori D, Nomura Y, Tanaka H. latrogenic acute aortic dissection during percutaneous coronary intervention for acute myocardial infarction. Ann Vasc Dis. 2012;5(1):78-81.

8. Khan MZ, Guzman L, Gharai LR, Exaire JE. Dissection of ascending aorta: a complication of Transradial artery access of coronary procedure. Heart Views. 2018:19(2):63-6.

9. Park KH, Lim C, Choi JH, Sung K, Kim K, Lee YT, Park PW. Prevalence of aortic intimal defect in surgically treated acute type a intramural hematoma. Ann Thorac Surg. 2008:86(5):1494-500.

10. Song JK. Update in acute aortic syndrome: intramural hematoma and incomplete dissection as new disease entities. J Cardiol. 2014;64(3):153-61.

\section{Publisher's Note}

Springer Nature remains neutral with regard to jurisdictional claims in published maps and institutional affiliations.
Ready to submit your research? Choose BMC and benefit from:
- fast, convenient online submission
- thorough peer review by experienced researchers in your field
- rapid publication on acceptance
- support for research data, including large and complex data types
- gold Open Access which fosters wider collaboration and increased citations
- maximum visibility for your research: over $100 \mathrm{M}$ website views per year
At BMC, research is always in progress.
Learn more biomedcentral.com/submissions 